\title{
BIODISPONIBILIDADE DA AZITROMICINA LIVRE E COMPLEXADA EM $\beta$-CICLODEXTRINAS
}

\section{Bioequivalence of azithromicyn free and complexed in $\beta$ - cyclodextrins}

\author{
Pasquini, N. $\mathrm{C}^{1^{*}}$; Pasquini, N. L. $\mathbf{S}^{2}$ \\ ${ }^{1}$ Instituto de Biociências, Departamento de Bioquímica e Microbiologia, UNESP -Universidade \\ do Estado de São Paulo. CEP : 13506-900, Rio Claro, São Paulo. \\ ${ }^{2}$ FUNEC - Faculdades Integradas de Santa Fé do Sul, Santa Fé do Sul, São Paulo.
}

Autor para correspondência e-mail: ncpasquini@rc.unesp.br

Recebido em 12/10/2007 - Aceito em 04/01/2008

RESUMO: Bioequivalence of azithromicyn free and complexed in $\beta$-cyclodextrins Ciclodextrinas (CDs) são oligossacarídeos cíclicos, não redutores, capazes de formar complexos de inclusão com outras moléculas, modificando suas características químicas e físicas.O objetivo deste trabalho é complexar azitromicina em $\beta$-ciclodextrinas $(\beta-C D)$ e testar in vivo sua liberação comparando com o fármaco comercial. As concentrações plasmáticas foram determinadas por cromatografia líquida acoplada ao detector de massa.

O estudo indica que as ciclodextrinas ou complexos de inclusão são estruturas que confere estabilidade a azitromicina, provoca liberação controlada e diminuição dos efeitos tóxicos.Diferenças foram observadas nas temperaturas de transição de fases e na morfologia dos cristais dos compostos puros (azitromicina/ $\beta-C D$ ) evidenciando complexação.As formulações com $\beta$-ciclodextrinas mostraram efeitos melhores que o fármaco livre, em termos de duração, é útil nas clinicas como fonte de interação paciente e tratamento, reduzindo assim a quantidade de fármaco administrada.

PALAVRAS-CHAVE: azitromicina, eficácia, $\beta$-ciclodextrinas

ABSTRACT: Cyclodextrins (CDs) are cyclic and non reducing oligosaccharids with the ability to form complexes with a wide range of hydrophobic molecules used in food, cosmetic and pharmaceutical industries.

The objective of this study is to complexation the azithromicyn in $\beta$-ciclodextrins $(\beta-C D)$ and test in vivo its release comparing with the commercial drug.

The plasmatic drug concentration was determined through mass-detection liquid chromatograpy. The study indicate the cyclodextrins or inclusion complexes are structures that confer stability to azithromycin, causing controlled release and redction of the toxic effects.Differences on phase transition temperature and structural changes in the crystal's patterns evidenced azitromicina/ $\beta-C D$ complexation. The formulations $\beta$-ciclodextrins had shown better effect that the free drug, in terms of duration, is useful in the clinics as a source interaction between patient and treatment, reducing the medicine's quantity of the patient.

KEYWORDS: azithromicyn, efficacy;, $\beta$-cyclodextrins 
Pasquini, N. C. et al./Revista Eletrônica de Farmácia Vol 5(1), 46-51, 2008.

\section{INTRODUÇÃO}

Ciclodextrinas (CDs) são grupos de oligossacarídeos obtidos a partir da degradação enzimática do amido e são conhecidas por modificarem as propriedades farmacológicas de vários fármacos através da formação de complexos de inclusão (DURAN et al., 2003). Devido a esta habilidade, as ciclodextrinas tornaram-se candidatas potenciais como sistema de liberação de fármacos (REN et al., 2002). As $\alpha, \beta$, $\gamma$-ciclodextrinas consistem de seis, sete e oito resíduos de $D$-glicose, respectivamente, unidas por ligações $\alpha-1,4$ glicosídicas. $O$ primeiro a citar ciclodextrinas foi Villiers (1891) quando estudava a digestão do amido com Bacillus amylobacter isolou 3 gramas de uma substância cristalina, de composição $\left(\mathrm{C}_{6} \mathrm{H}_{10} \mathrm{O}_{5}\right)_{2} \cdot 3 \mathrm{H}_{2} \mathrm{O}, 0$ qual chamou de celulosine devido a semelhança com celulose. Cramer (1954) direcionou os estudos para as propriedades dos complexos de inclusão formados como as CDs. As $\beta$-CD naturais contém as seguintes propriedades físico-químicas: peso molecular 1135 , número de unidades de glicose 7, diâmetro interno da cavidade $(\AA)$ 6,0-6,05, diâmetro externo da cavidade (A) 15,4 , solubilidade em água)g $/ 100 \mathrm{~mL}$ ) $25^{\circ} \mathrm{C} 1,85$, volume da cavidade $\left(\AA^{3}\right) 262$ (LOFTSSON \& BREWSTER, 1996).

$\mathrm{Na}$ indústria farmacêutica as ciclodextrinas são largamente utilizadas, consta na literatura uma variedade de fármacos complexados como, Clotrimazol (BILENSOY et al., 2006), Dorzolamida (SIGURDSSON et al., 2005) e $\beta$-lapachona (NASONGKALA et al., 2003).

A complexação de um fármaco em CDs ocorre modificações em suas propriedades químicas e físicas. Modificações estas que são vantajosas podendo citar: formação de fármacos para ingestão oral-transformar compostos líquidos em cristalino; mascarar produtos com sabor ou aroma desagradável; reduzir a higroscopicidade, etc; meljorar a estabilidade química - diminuição da perda por evaporação de compostos voláteis; proteger contra a oxidação do ar; reduzir a sensibilidade à luz, ao calor, aos gástricos, etc; melhorar a biodisponibilidade de fármacos de baixa solubilidade - aumento da taxa de dissolução; aumento ou redução dos níveis do fármaco na corrente sangüínea; liberação controlada do princípio ativo; formulação de injeções, soluções oculares, etc. - preparação de fármacos insolúveis em água sem solventes orgânicos; redução dos efeitos colaterais, irritações locais ou efeitos hemolíticos e comprimidos - fácil dissolução do comprimido na água (SZEJTLI, 1988; DUCHÊNE, 1988) ou apenas para fins estéticos (RODINELLI, 2005).

Azitromicina é o primeiro de uma nova classe de antibióticos, os, que se originaram dos macrolídeos. Foi sintetizado a partir da eritromicina sendo acrescentado um átomo de nitrogênio ao anel lactâmico. Esta alteração aumentou a sua biodisponibilidade nos tecidos e a sua difusão, e com isto, a azitromicina pode atingir concentrações nos tecidos e nos polimorfonucleares de 50 a 79 vezes (DEF, 2006). A fórmula molecular da azitromicina é $\mathrm{C}_{38} \mathrm{H}_{72} \mathrm{~N}_{2} \mathrm{O}_{12}$ e seu peso molecular é 785 daltons. Azitromicina inibe a síntese protéica bacteriana através da ligação com a subunidade ribossomal $50 \mathrm{~S}$. Demonstra atividade in vitro contra diversas bactérias aeróbia Gram positivas e Gram negativas (SORIANO, 1995).

O objetivo deste trabalho é encapsular azitromicina em ciclodextrinas e testar in vivo sua liberação comparando com o fármaco comercial.

\section{MATERIAIS E MÉTODOS}

Solução Padrão: Em um balão de $100 \mathrm{~mL}$ colocou $0,0100 \mathrm{~g}$ de azitromicina e dissolveu em metanol para obtenção de concentração igual a $100 \mu \mathrm{g} / \mathrm{ml}$. Padrão interno em um balão de 100 $\mathrm{mL}$ colocou $0,0100 \mathrm{~g}$ de eritromicina e dissolveu em metanol para obtenção de concentração igual a $100 \mu \mathrm{g} / \mathrm{ml}$.

Condições cromatográficas: As corridas cromatográficas foram realizadas em uma coluna analítica Lichrossorb RP-18 $10 \mu \mathrm{m}(250 \times 4 \mathrm{~mm})$ e uma pré coluna Securityguard ${ }^{\mathrm{tm}} \mathrm{C}_{18} 10 \mu \mathrm{m}$ $(4 \times 3,0 \mathrm{~mm})$, pressão entre 60 a $70 \mathrm{Kgf}$ e com fluxo de $1 \mathrm{~mL} / \mathrm{min}, 23^{\circ} \mathrm{C}$ a temperatura do autoinjetor e volume de injeção em $10 \mu \mathrm{l}$. O tempo de corrida foi ajustado para 6,0 minutos.

Condições de detecção no espectrômetro de massa: Fonte de ionização por electrospray positivo (ES+), a análise foi desenvolvida no modo MS/MS com $40 \mathrm{~V}, 30 \mathrm{eV}$ e $3,5 \mathrm{KV}$ para energia de cone, energia de colisão e capilar respectivamente. Foram monitorado os íons $\mathrm{m} / \mathrm{z}$ 591 e m/z 158 para azitromicina e m/z 576 e m/z 158 para eritromicina (ABREU, 2003).

Os complexos de inclusão do fármaco azitromicina com $\beta$-CD (Sigma Chemical Company Ltda-UK), foram preparados dissolvendo o fármaco ( $5 \mathrm{mg}$ ) em $10 \mathrm{~mL}$ de tampão salina (HEPES $10 \mathrm{mM} / \mathrm{NaCl} 120 \mathrm{mM}$ ) e misturado à solução de $\beta-C D$ com uma razão molar de $1 / 10$ sob agitação em ambiente escuro a $25^{\circ} \mathrm{C}$ por 48 horas, liofilizado e armazenado em dessecador.

Foram utilizados 12 cães Beagle, todos do sexo masculino, sadios, pesando entre 20 a $25 \mathrm{Kg}$, os animais foram mantidos em ambiente com temperatura e luminosidade controladas e 
alimentados com ração padrão. O estudo clinico foi conduzido segundo delineamento aleatóreo, cruzado, aberto de dois períodos, com intervalo de 30 dias. Foram coletado $1 \mathrm{~mL}$ de sangue e colocadas em tubos sem anticoagulante, $1,2,3,4,5,6,7,8,9,12,16$ e 18 horas após administração oral do fármaco $(5 \mathrm{mg})$ encapsulado em $\beta$-ciclodextrinas ou não. Após a coleta colocou o plasma $(200 \mu \mathrm{l})$ em tubos eppendorf, adicionou $20 \mu \mathrm{l} \mathrm{de} \mathrm{NaOH} 1 \mathrm{~mol} / \mathrm{l}, 20 \mu \mathrm{l}$ de eritromicina, misturou em vórtex por 15 segundos, adicionou $800 \mu \mathrm{l}$ de éter etílico e agitou em vótex por 15 segundos, as amostras foram centrifugadas a $4000 \mathrm{~g}$ por 10 minutos, a fase orgânica foi seca sob o fluxo de nitrogênio, o resíduo foi ressuspendido em $800 \mu \mathrm{l}$ de acetonitrila, transferiu a solução para vials que foram colocados em estantes de tubos para auto-injetor SHIMADZU. A curva padrão foi construída de uma amostra do plasma sem fármaco ao qual foram acrescentadas concentrações conhecidas do padrão. As concentrações plasmáticas das amostras foram derivadas a partir da equação de regressão da reta obtida com a curva padrão (concentração do fármaco em função da razão das áreas). Para determinar a concentração da azitromicina procedeu de acordo com Abreu 2003.

Os complexos de inclusão foram caracterizados em solução e em estado sólido. No primeiro caso, os complexos foram analisados por espectrofotometria UV/visível para o acompanhamento da cinética de complexação dos fármacos e ressonância magnética nuclear ( $\left.{ }^{1} \mathrm{H}-\mathrm{NMR}\right)$ para confirmar a complexação dos fármacos, no segundo caso usou calorimetria diferencial de varredura (DSC) para confirmar a inclusão. No experimento de DSC foi utilizado $10 \mathrm{mg}$ de amostras aquecidas a uma velocidade de $10^{\circ} \mathrm{C} / \mathrm{min}$., numa faixa de $30-220^{\circ} \mathrm{C}$. A calibração do instrumento foi feita com índio. Foram realizadas análises na proporção 1:1, 1:2 e 1:4 nas amostras de azitromicina complexadas com ciclodextrinas. Algumas evidências da ocorrência de inclusão podem ser obtidas pela análise térmica dos complexos. Quando a molécula hóspede se insere na cavidade de ciclodextrinas, o seu ponto de fusão ou sublimação geralmente se desloca para temperatura diferentes ou desaparecem dentro da faixa de temperatura onde a ciclodextrinas se decompõe (FROMMING et. al., 1994).

Todos os resultados relativos à concentração da azitromicina foram expressos em termos de média e erro padrão da média. Os parâmetros analisados foram: $C_{\text {máx }}(\mathrm{ng} / \mathrm{mL}), C_{\text {máx- }}$ final gh $(\mathrm{ng} / \mathrm{mL})$, e $T_{\max }(\mathrm{h})$. Os resultados obtidos com os fármacos livre ou encapsulado foram submetidos à Análise de Variância (ANOVA). Foi utilizado intervalo de confiança (IC) de $95 \%$ para razão entre as medias dos valores obtidos com os fármacos.

\section{Citotoxicidade}

Foram utilizadas células de fibroblastos da linhagem V79, clone M8, de pulmão de hamster. As células foram cultivadas em meio de DMEM, contendo $90 \mathrm{U} / \mathrm{mL}$ de penicilina G, 90 $\mathrm{\mu g} / \mathrm{mL}$ de estreptomicina e soro fetal bovino (10\%) em atmosfera umedecida com $6 \%$ de $\mathrm{CO}_{2}$ a $35^{\circ} \mathrm{C}$. Nos ensaios de viabilidade celular, 80 poços de placas de cultura de células foram inoculadas com $3.10^{4}$ células a $35^{\circ} \mathrm{C}$ por 50 horas. $O$ meio foi removido e reposto com meio tratado do material a testar. As células foram incubadas por 26 horas, em seguidas aspiradas. O teste da redução do brometo de tetrazolium 3-(4,5-dimetiltiazol-2-il)-2,5-bifenil (MTT) foi realizado adicionando o corante na concentração de $1 \mathrm{mg} / \mathrm{gL}$ e incubando por 6 horas. O meio foi retirado e adicionado etanol para solubilizar o formazan. Após 15 minutos de agitação realizou a leitura no espectrofotômetro em 570 nm (Denizot \& LANG, 1986). Foram testadas amostras de azitromicina livre, azitromicina/LUV, azitromicina/ $\beta-C D, \beta-C D$ e LUV. A redução enzimática do brometo de tetrazolium provém do succinato desidrogenase mitocondrial das células, decorrente disto a redução do MTT indica a função mitocondrial.

\section{RESULTADOS E DISCUSSÃO}

Na Figura 1 pode ser observadas as médias das concentrações plasmáticas em cada tempo de estudo para as formulações testadas. A Figura 1 mostra que azitromicina/ $\beta-C D$ apresentou um pico inferior a azitromicina livre, mas permaneceu por muito mais tempo na faixa de ação do fármaco. Os parâmetros $C_{\text {máx }}(\mathrm{ng} / \mathrm{mL})$ e $C_{\text {máx-final }}$ gh $(\mathrm{ng} / \mathrm{mL})$ apresentaram a média geométrica 78,7, 52,9 e 2,2, 30,2; $T_{\max }$ (h) 2, 4 para azitromicina livre e azitromicina/ $\beta$ CD respectivamente. 


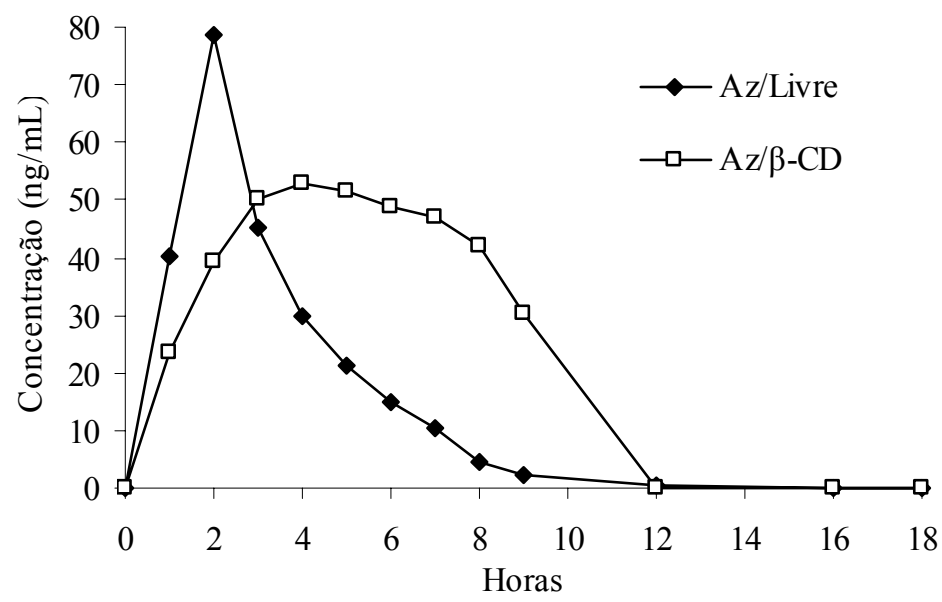

Figura 1: Curva da concentração plásmatica média vs tempo de 12 cachorros.

Fazendo uso de células V79, fizemos um screening de toxicidade da azitromicina e azitromicina/ $\beta-C D$ onde observou que a $\beta-C D$ diminui o efeito tóxico que a azitromocina apresenta (Figura 2).

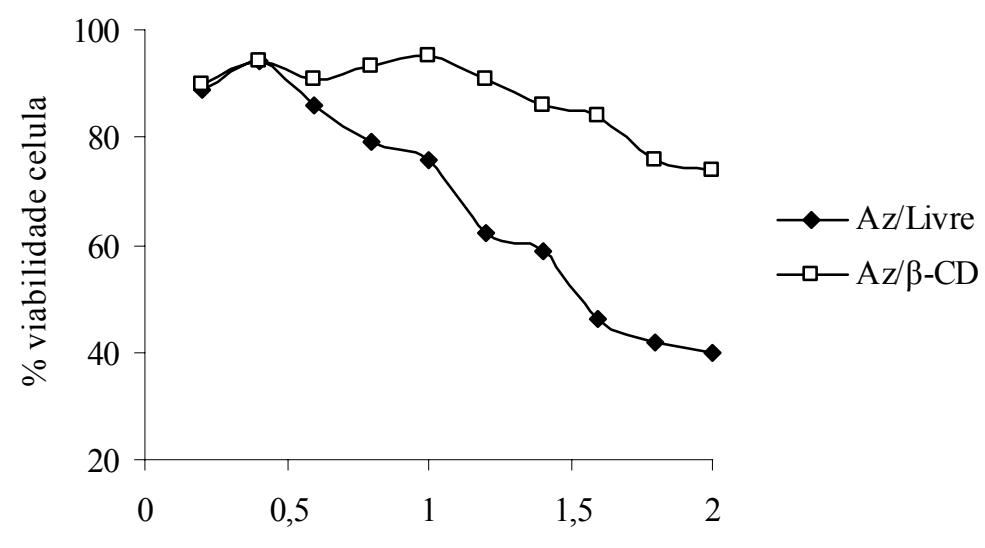

Concentração de azitromicina $\mathrm{mM}$

Figura 2: Viabilidade celular após tratamento com azitromicina livre e encapsulado em $\beta-C D$.

Os resultados de ${ }^{1} \mathrm{H}$-RMN mostraram a formação do complexo de inclusão devido mudança no deslocamento dos sinais nos prótons $\mathrm{H}^{3}(3,528$ para 3,433$) \mathrm{H}^{5}(3,568$ para 3,697$)$ e $H^{6}(3,721$ para 3,538$)$. Segundo Schneider (1998) os prótons $H^{3}$ e $H^{5}$ que estão dentro da cavidade da $\beta$-ciclodextrina são as que mais sofrem alterações na inclusão de moléculas hóspedes, sendo $\mathrm{H}^{3}$ mais sensível que $\mathrm{H}^{5}$. Assim podemos afirmar que houve interação entre azitromicina e a cavidade da $\beta-C D$, apontando para formação de complexo estável.

Segundo Szejtli (1988) as ciclodextrinas não apresentam ponto de fusão definido e acima de $200^{\circ} \mathrm{C}$ começam a se decompor. As propriedades termoanalíticas que influem são grau de aquecimento, teor de água, estrutura cristalina e atmosfera gasosa dos ensaios. Em geral a complexação é verificada pelo desaparecimento do pico endotérmico característico da molécula encapsulada. Esse desaparecimento pode ser atribuído ao estado amorfo, à formação do complexo, ou ambas (LIN \& KAO, 1989).

Observando os termogramas (Figura1) nota-se a inclusão da azitromicina na cavidade da $\beta-C D$ pelo desaparecimento total do pico referente ao fármaco livre, na razão estequiométrica 1:1.

$\mathrm{Na}$ espectrofotometria UV/visível, permitiu não somente identificar a presença dos complexos de inclusão em solução, mas também caracterizar a cinética (Figura 3 ) de complexação pelos perfis de absorbância em função do tempo (LIMA, 2001). Os perfis mostram que a complexação de azitromicina estabilizou em 20 horas, a complexação e estabilização foi independente da concentração de $\beta$-CD no meio, confirmando a razão estequiométrica 1:1 observada nas análises de DSC. 


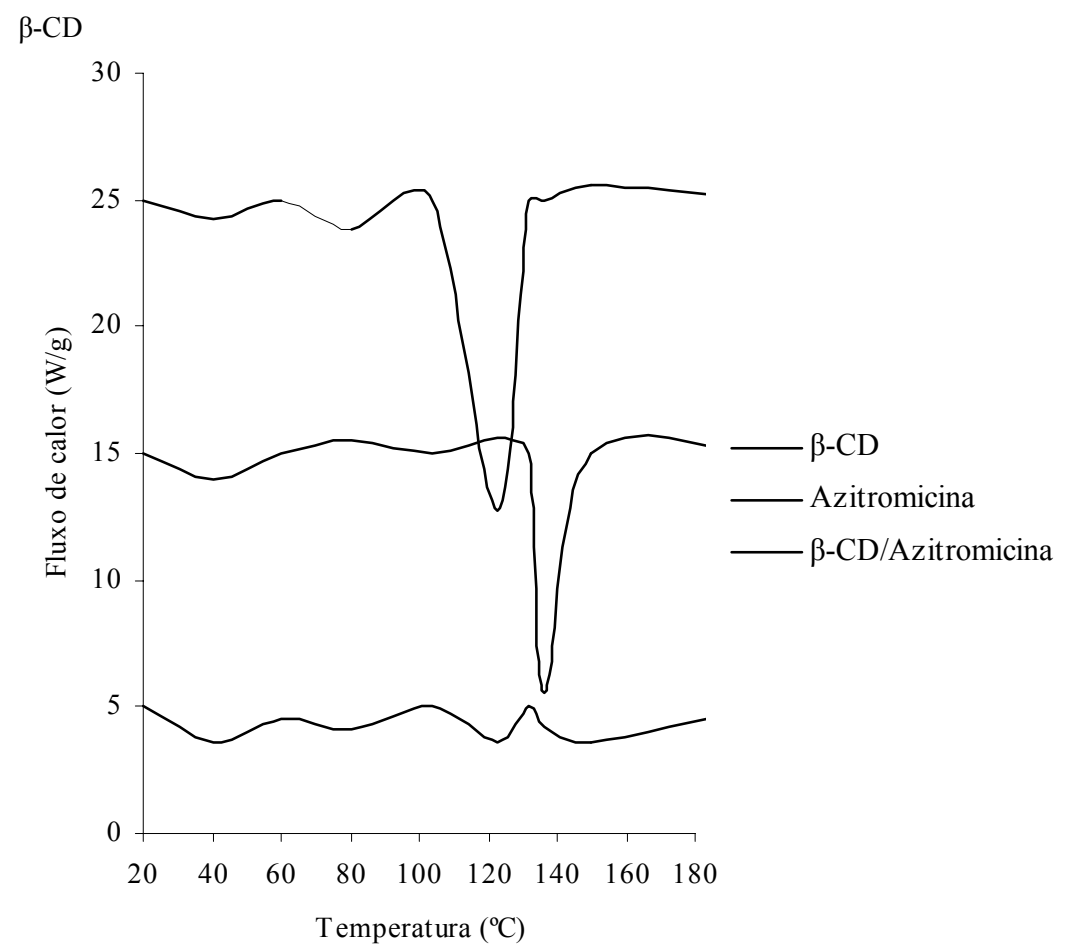

Figura 3 :Diagramas de calorimetria diferencial de varredura para B-CD livre, azitromicina livre e B-CD/azitromicina

\section{CONCLUSÃO}

A liberação controlada propõe muitas vantagens quando comparado ao sistema de administração de fármaco de modo convencional. Na administração convencional a concentração do fármaco na corrente sanguínea apresenta um pico e depois declina. Toda droga contém uma faixa de ação terapêutica, onde abaixo da faixa ela se torna ineficaz e acima tóxica. A complexação em ciclodextrinas permite a vetorização da droga no intuito de manter a concentração em níveis terapêutica por um longo tempo. Fato confirmado em nossas análises.

O projeto vem ao encontro da necessidade do desenvolvimento de novas formas farmacêuticas para agentes antimicrobianos de ação comprovada, com a intenção de melhorar a terapêutica através de uma possível diminuição da dose e de uma melhor aão antimicrobiana contra os agentes patogênicos, melhorando assim as opções de terapêutica disponíveis e com impacto positivo sobe a saúde pública (TORRES, 2005).

O desenvolvimento de complexação de fármacos $\beta$-ciclodextrinas é promissor, e representa uma melhora na adesão ao tratamento. O beneficio esta no aumento do índice terapêutico dos fármacos no plasma e redução da administração.

\section{REFERENCIAS BIBLIOGRÁFICAS}

ABREU, L.R.P. Estudos de farmacocinética comparada em voluntários sadios. 2003. 167p. Tese (Doutorado) Departamento de Farmacologia, Universidade de Campinas, Campinas.

BILENSOY, E; et al.. Mucoadhesive, thermosensitve, prolonged-release vaginal clotrimazole: $\beta$ cyclodextrin complex. AAPS Pharm SciTech., v.7, p.E1-E7, 2006.

CRAMER, F. (1954). Einschlussverbindunger (Inclusion compounds). Springer-Verlag, Berlin.

DENIZOT, F.; LANG, R. Rapid colorimetric assay for cell growth amd survival. Modifications to the tetrazolium dye procedure giving improved sensivity and reliability. J. Immunol. Methods. v. 89, p. 271-277, 1986.

DICIONARIO DE ESPECIALIDADE FARMACEUTICA - DEF, 2006.

DUCHÊNE,D. New trends in pharmaceutical applications of cyclodextrins inclusion compounds. In: Huber, O. and Szejtli, J. eds. Proceedings of the fourth international symposium on cyclodextrins, Kluwer Academic Publishers, Dordrecht, p. 265275, 1988.

DURÁN, N.; Evaluation of the antiulcerogenic activity of violacein and its modulation by the inclusion complexation with beta-cyclodextrin. Can. J. Physiol. Pharmacol., v.81, p.387-396, 2003. 
FROMMING, K.H.; SZEJTLI, J. Topics in inclusion sciense-cyclodextrins in pharmacy, Hungria: Ed. Kluwer Acdemic Publishers, 2002.

LIMA, H.O.S. Estudo da encapsulação de fármacos de primeira linha no tratamento da turbeculose em lipossomas e ciclodextrnas.2001.188 p. Faculdade de Engenharia Química, Universidade de Campinas, Campinas.

LIN, S.Y.; KAO, Y.H. Solid particulates of drug- $\beta-C D$ inclusion complexes directly prepared by a spray-drying technique. Int. J. Pharm. vol. 56, p.249259, 1989.

LOFTSSON, T; BREWWSTER, M.E. Pharmaceuticals applications of cyclodextrins 1. Drug solubilization and stabilization. J. Pharm. Sci. 85 : 1017-1025, 1986.

Nasongkala, $\mathrm{N}$; et al.. Enhancement of Solubility and Bioavailability of $\beta$-Lapachone using Cyclodextrin Incluion Complex. Pharmaceutical research, v.20, n.10, p.1626-1633, 2003.

Schneider, H.J.; et al.. NMR studies of cyclodextrins and cyclodextrin complexes. Chem Rev. p. 1755-1785, 1998.

SILVA, P., Farmacologia. 6 ed. Rio de Janeiro: Guanabara Koogan, 2002.,

SORIANO, F. Antimicobial susceptibilities of Cornebacterium species and other non-sporeforming Gram-positive to 18 antimicrobial agents. Antimicrob. Ag Chemother, v.39 (1): 208-214, 1995.

REN, X.; et al.. Anovel cyclodextrin-derived tellurium compound with glutathione peroxidase activity. Chembiochem. V.3, p.356-363, 2002.

RODINELLI, B. O.; LIMA, E. M.. Avaliação do perfil de liberação do enalapril em comprimidos revestidos com HPMC. Revista Eletrônica de Farmácia, v. 2(2), 37-40, 2005.

Sigurdsson, H.H.; et al.. Cyclodextrin formulations of dorzolamide and its distribution in the eye after topical administration. Journal of Controlled Release, v.102, p. 255-262, 2005.

Szejtli, j. Cyclodextrin technology, Kluwer Academic Publishers, Dordrecht, 1988.

TORRES, L. M. S., LIMA, E. M. Avaliação de efeito antimicrobiano in vitro de cefalosporinas em lipossomas unilamelares. Revista Eletrônica de Farmácia, v. 2(2), 218-220, 2005. 